\title{
Construction and functional identification of a hepatitis $B$ virus $S$ protein small hairpin RNA recombinant adenovirus
}

\author{
S. Wang ${ }^{1 *}$, Y.Z. Liu ${ }^{2 *}$, D.D. Qin ${ }^{1}$, C.C. Zou ${ }^{1}$, Y.R. Sheng ${ }^{1}$ A.L. Huang ${ }^{1}$ \\ and H. Tang ${ }^{1}$
}

${ }^{1}$ Key Laboratory of Molecular Biology on Infectious Diseases, Ministry of Education, Second Affiliated Hospital, Chongqing Medical University, Chongqing, China

${ }^{2}$ Department of Forensic Medicine, Chongqing Medical University, Chongqing, China

*These authors contributed equally to this study.

Corresponding author: H. Tang

E-mail: tanghua86162003@aliyun.com

Genet. Mol. Res. 13 (2): 3495-3501 (2014)

Received May 28, 2013

Accepted October 10, 2013

Published February 25, 2014

DOI http://dx.doi.org/10.4238/2014.February.25.4

\begin{abstract}
Hepatitis B virus S protein (HBs) plays an important role in hepatocellular carcinoma progression. However, to date, no direct and effective methods exist to research the function of HBs. Here, we combined the technology of RNA interference with recombinant adenovirus, constructed a recombinant adenovirus-expressing small hairpin RNA of HBs, and infected HepG2.2.15 cells. Then, reverse transcriptionpolymerase chain reaction (RT-PCR), quantitative real-time PCR, enzymelinked immunosorbent assay, and Western blot analysis were performed to verify the interference effects. As a result, a recombinant adenovirus was successfully constructed and effectively packaged in AD293 cells, and it significantly inhibited HBs mRNA and protein expression in vitro. Our study may provide a novel tool to study HBs function.
\end{abstract}

Key words: Hepatitis B virus S protein small hairpin RNA; Hepatitis B virus S protein; Recombinant adenovirus 


\section{INTRODUCTION}

Hepatitis B virus infection is a major global health problem. Worldwide, an estimated two billion people have been infected with the hepatitis B virus, and about 600,000 people die every year because of the acute or chronic consequences of hepatitis B (Margolis, 1998). After viral nucleocapsids enter the cell, covalently closed circular DNA is formed and translated into viral pre-core antigen $(\mathrm{C}$, pre-C); polymerase $(\mathrm{P})$; envelope large $(\mathrm{L})$, medium $(\mathrm{M})$, and small (S) surface proteins, and trans-activating protein $(\mathrm{X})$, which play different roles in hepatocellular carcinoma progression. However, hepatitis B virus S protein (HBs), an important functional protein, has been little studied.

The emergence of reverse genetics shed light on the research of HBs. Small hairpin RNA (shRNA) could be cleaved into 19-23-nucleotide dsRNA fragments known as small interfering RNAs (siRNAs) and cause sequence-specific degradation of homologous mRNAs (Elbashir et al., 2001, 2002). The polymerase III promoter U6 could be used to achieve robust shRNA expression.

However, existing methods relying on liposomal transfection are either inefficient or unsuitable for use in animals. Therefore, an efficient intracellular delivery system is urgently needed for shRNAs or vectors expressing the corresponding shRNAs. The adenovirus vector may be a good candidate because it can efficiently deliver exogenous genes into cells without insertional mutagenesis (Hitt et al., 1997).

Here, the novel AdEasy system was utilized to construct an shRNA expression vector (Luo et al., 2007). It is supported by a high titer virus packaged in AD293 cells and inhibition effects in HepG2.2.15 cells. This system provides strong support for its use in functional studies of HBs.

\section{MATERIAL AND METHODS}

\section{Materials}

AD293 cells and the HepG2.2.15 human hepatocarcinoma cell line were purchased from American Type Culture Collection (USA). pAdTrack-CMV and pADEasy-1 were kept by our laboratory, pGenesil-HBs-shRNA was constructed and kept by our laboratory, and DH-5 $\alpha$ and BJ5183 competent cells were kept by our laboratory. Horse polyclonal antibody to hepatitis B virus surface antigen (Ad/Ay) was purchased from Abcam (USA).

\section{Construction of recombinant adenovirus vectors}

The AdEasy system was used to rapidly generate recombinant adenovirus (Luo et al., 2007). First, the shRNA-expressing cassette of HBs containing the U6 promoter was obtained from our existing plasmid pGenesil-HBs-shRNA by double digestion with HindIII and SalI. The target sequence against HBs was designed as follows: 5'-GGTGGACTTCTCTCAATTT-3'. Second, the target was sub-cloned, and the resulting shuttle vector was pAdTrack-CMV-U6HBs-shRNA. Then, after linearization by PmeI, homologous recombination with pADEasy-1 was carried out in BJ5183 competent cells to obtain the recombinant adenovirus plasmid AdU6-HBs-shRNA. 


\section{Packaging, amplification, and titer determination of recombinant adenovirus}

The standard operation was followed from Nature protocols (Luo et al., 2007). The positive recombinant was linearized with $\mathrm{PacI}$ and transfected into AD293 cells for virus packaging and amplification. Virus supernatant was collected when $80 \%$ cells showed the cytopathic effect (CPE). A micro-dose CPE assay was employed to determine the virus titer. The virus was serially diluted to concentrations of $10^{-2}, 10^{-3}, 10^{-4}, 10^{-5}, 10^{-6}, 10^{-7}, 10^{-8}$, and the dilutions were used to infect A293 cells on 96-well plates $\left(10^{4}\right.$ cells/well) with $200 \mu \mathrm{L}$ Dulbecco's modified Eagle's medium (DMEM, USA). The CPE was monitored by fluorescence microscopy. The virus titer was calculated as follows: virus titer $(\mathrm{PFU} / \mathrm{mL})=$ seeded cells $\mathrm{x}$ optimum dilution of virus x 10/virus volume added.

\section{Cell culture and infection}

Cells were cultured with $10 \%$ fetal bovine serum (GIBCO, USA), penicillin (100 U/ $\mathrm{mL})$ and streptomycin $(100 \mu \mathrm{g} / \mathrm{mL})$ at $37^{\circ} \mathrm{C}$ in a $5 \% \mathrm{CO}_{2}$ atmosphere. HepG2.2.15 cells were cultured in minimum essential medium (Hyclone, China) and $5 \mathrm{mM}$ glutamine, while AD293 cells were cultured in DMEM. According to the virus titer that was determined, the optimum virus dilution was selected to infect HepG2.2.15 cells. An existing adenovirus, Ad-HK, was used for interference control.

\section{Reverse transcription-polymerase chain reaction (RT-PCR) and quantitative real- time PCR (qRT-PCR) analysis}

Seventy-two hours after infection, total RNA was isolated using Trizol reagent (Invitrogen, USA), and $1 \mu \mathrm{g}$ total RNA was used to synthesize cDNA using the PrimeScript RT reagent kit (Takara, Japan) following manufacturer instructions. The amplification was performed using GoTaq Green Master Mix (Promega, USA) for 28 cycles with an initial denaturation at $94^{\circ} \mathrm{C}$ for $3 \mathrm{~min}$, denaturation at $94^{\circ} \mathrm{C}$ for $30 \mathrm{~s}$, annealing at $57^{\circ} \mathrm{C}$ for $30 \mathrm{~s}$, extension at $72^{\circ} \mathrm{C}$ for $30 \mathrm{~s}$, and a final extension at $72^{\circ} \mathrm{C}$ for $5 \mathrm{~min}$. The PCR products were analyzed on $1 \%$ agarose gel using a GELDOC 2000 system (Bio-Rad, USA). The primers were as follows: $\beta$-actin, F: 5'-GTGGATCAGCAAGCAGGAGT-3' and R: 5'-TGTGTGGACTTGGGAGAGGA-3'; and HBs, F: 5'-ATGGAGAACATCAC ATCAGG-3' and R: 5'-GCAATGTATACCCAGAGACAAAA-3'. For qRT-PCR, $1 \mu \mathrm{L}$ cDNA (10-fold dilution), $10 \mu \mathrm{L}$ SYBR green mix, and $1 \mu \mathrm{L}$ forward and reverse primers $(10 \mu \mathrm{M})$ in a total volume of $20 \mu \mathrm{L}$ were applied. The standard PCR condition was used. Relative changes in gene expression were calculated using the $2^{-\Delta \Delta \mathrm{CT}}$ method (Livak and Schmittgen, 2001).

\section{Enzyme-linked immunosorbent assay (ELISA) analysis}

HBs antigen (Ag) that was secreted in the supernatant between 24 and $72 \mathrm{~h}$ was collected and detected using the diagnostic ELISA kit according to the manufacturer (Kehua Biotech, Shanghai, China) protocol. 


\section{Western blot analysis}

Seventy-two hours after infection, cells were collected and lysed in protein lysis buffer. The bicinchoninic acid protein concentration determination kit (Beyotime, China) was used to determine the protein concentration. Equal amounts of total protein were separated by $10 \%$ sodium dodecyl sulfate polyacrylamide gel electrophoresis and then transferred to a polyvinylidene fluoride membrane. The membrane was blocked in 5\% nonfat dry milk in TrisHCl-buffered saline supplemented with $0.5 \%$ Tween 20 for $3 \mathrm{~h}$ followed by primary antibody (Horse polyclonal antibody to HBs, diluted 1:500; monoclonal antibody to $\beta$-actin, diluted 1:6000) overnight. The membrane was then incubated with secondary antibody conjugated with horseradish peroxidase (HBs, diluted 1:1000; $\beta$-actin, diluted 1:6000) and visualized by the chemiluminescence $\mathrm{ECL}^{\mathrm{TM}}$ detection system (Pierce, USA).

\section{Statistical analysis}

All statistical analyses were carried out using the Student $t$-test. Data are reported as means \pm standard deviation. The significance was defined as $\mathrm{P}<0.05$.

\section{RESULTS}

The HBs shRNA-expressing cassette containing the U6 promoter was successfully obtained and sub-cloned into the shuttle vector pAdTrack-CMV, as shown in Figure 1A and B. A 400-bp fragment could be obtained from pGenesil-HBs-shRNA and pAdTrack-CMV-U6HBs-shRNA by a double digestion with HindIII and SalI. Successful recombinants of the shuttle vector and backbone plasmid were verified by PmeI linearization; as a result, fragments of approximately 20,000 and $4500 \mathrm{bp}$ were obtained (Figure 1C).

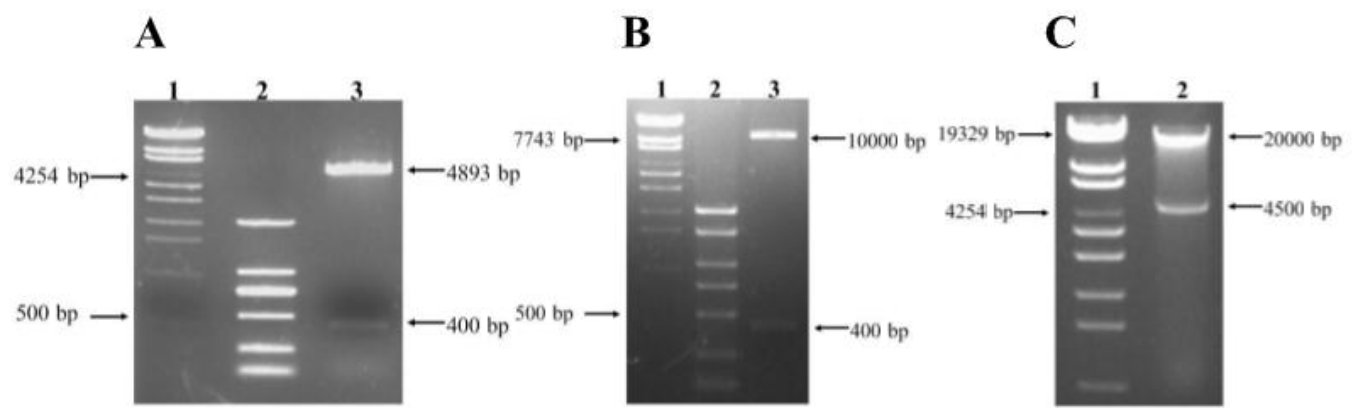

Figure 1. Identification of recombinant adenovirus vectors. A. Double digestion of interference plasmid pGenesilHBs-shRNA; B. verification of recombinant shuttle vector pAdTrack-CMV-U6-HBs-shRNA; C. recombinant of shuttle vector with virus backbone vector successfully constructed by Pac linearization.

After infection with different concentrations of virus, the CPE was monitored by fluorescence microscopy. As a result, the $10^{-6}$ dilution had the optimum effect, and $95 \%$ of cells were round and more than $50 \%$ of cells were shedded. The virus titer was $5 \times 10^{11} \mathrm{PFU} / \mathrm{mL}$.

Twenty-four hours after infection, the HepG2.2.15 cell infection efficiency was moni- 
tored by fluorescent signal detection using fluorescence microscopy. As shown in Figure 2, about $90 \%$ of cells could be effectively infected.

\section{White}

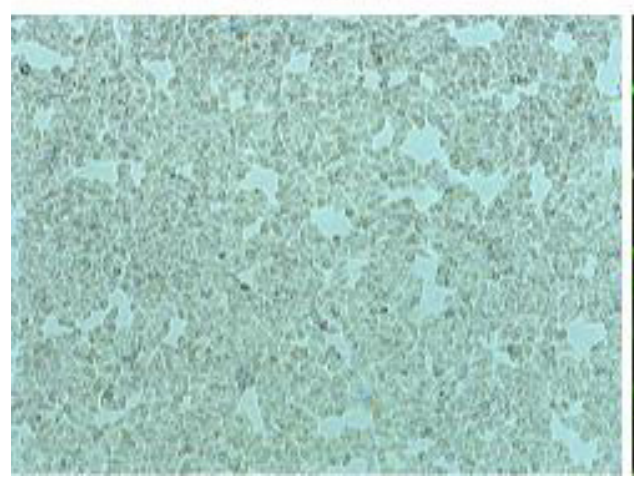

Fluorescent

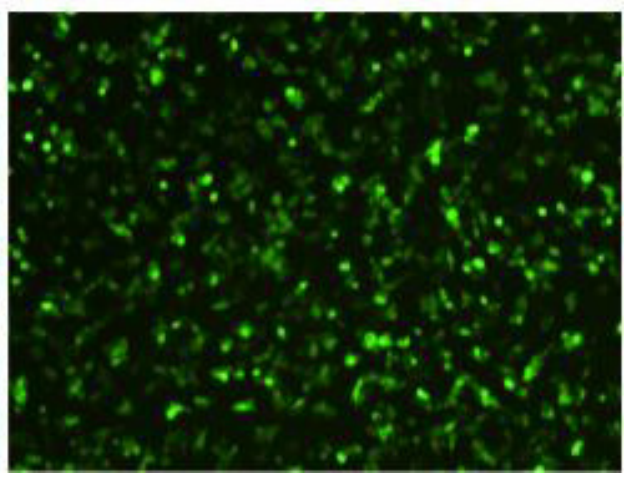

Figure 2. EGFP expression used to identify the infection effect.

To identify the inhibition effect of recombinant adenovirus, HepG2.2.15 cells were infected for 3 days, and total RNA was isolated. Then, RT-PCR and qRT-PCR were performed to analyze the HBs mRNA expression. Consequently, the HBs mRNA expression could be significantly inhibited by Ad-HBs-shRNA by about $60 \%$ (Figure $3 \mathrm{~A}$ and $\mathrm{B}$ ).
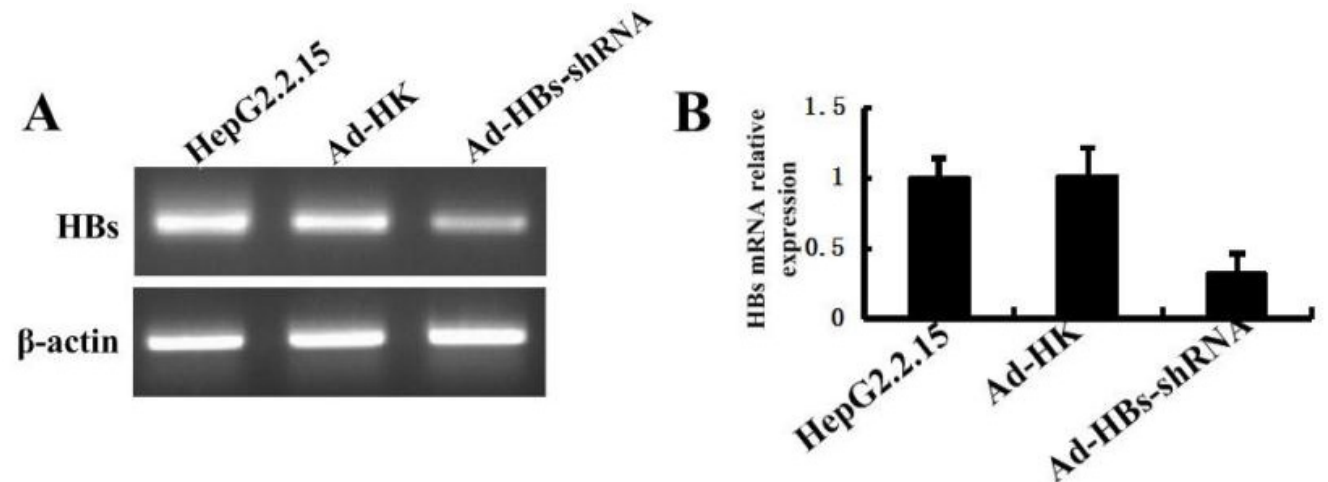

Figure 3. Recombinant adenovirus interference effect on mRNA level. A. RT-PCR performed to confirm the inhibition effect; B. qRT-PCR performed to confirm the inhibition effect. The groups of HepG2.2.15 cells without virus infection and infected with Ad-HK were used as negative control.

Furthermore, HBs protein expression was checked by ELISA and Western blot. As a result, HBs Ag that was secreted into the cell supernatant was about 50\% lower in the AdHBs-shRNA group than in the Ad-HK group (Figure 4A, $\mathrm{P}<0.01$ ). In addition, two forms of small HBs Ags, gp27 and p24, were detected and significantly inhibited in the Ad-HBsshRNA group compared to that in the Ad-HK group (Figure 4B). 
A

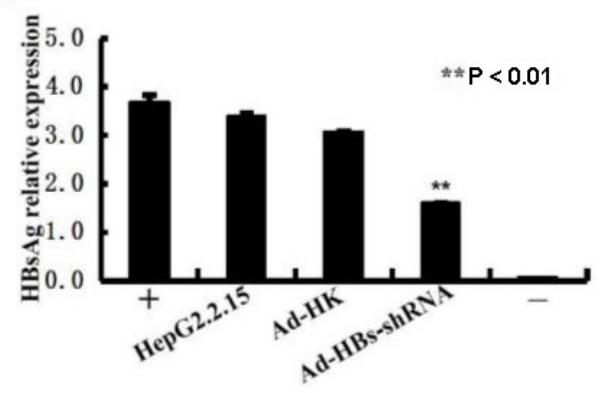

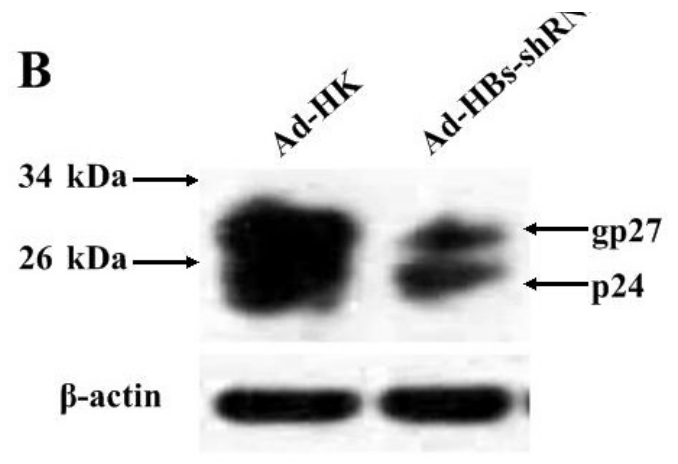

Figure 4. Recombinant adenovirus interference effect on protein level. A. ELISA was carried out to analyze the inhibition effect for HBsAg. (+) and (-) represent positive and negative control, respectively, in ELISA kits; B. Western blot was performed to analyze the inhibition effect for HBs protein expression. Actin was used as a loading control.

\section{DISCUSSION}

Recently, considerable attention has been directed toward the use of RNA interference as a method of therapy and basic biological research (Guo and Kemphues, 1995; Kapadia et al., 2003). Recombinant adenoviruses are replication-defective adenoviral vectors that have proven to be useful for gene therapy, vaccine therapy, and basic biology (McConnell and Imperiale, 2004). In this study, we combined the technology of RNA interference with recombinant adenovirus, and developed virus delivery vectors expressing the HBs-shRNA cassette. As a result, the shRNA of HBs was delivered into HepG2.2.15 cells efficiently by a viral vector, sequence-specific degradation of homologous mRNAs occurred, and the mRNA and protein expression of HBs was inhibited about 60 and 50\%, respectively, within $72 \mathrm{~h}$.

We checked the HBs Ag secretion into the supernatant at 24, 48, and $72 \mathrm{~h}$; the inhibition of HBs Ag by shRNA was modest within $48 \mathrm{~h}$, but it increased $72 \mathrm{~h}$ after infection. This is an expected finding when a plasmid structure instead of an siRNA molecule is introduced into the cells. The hairpin structure is successively produced by cellular RNA polymerase III and cleaved by Dicer into a ds-siRNA molecule. After all of these steps, the siRNA could affect the targeted HBs mRNA (Paddison et al., 2002). Furthermore, in order to truly reflect the inhibition of Ad-U6-HBs-shRNA, the culture medium was changed $24 \mathrm{~h}$ after infection to remove the secreted $\mathrm{HBs} \mathrm{Ag}$ in the control groups before the function of shRNA in the experimental group.

Although the system that we generated is efficient for HBs function research, there are some limitations to the application. First, long-term inhibition could not be achieved because of the non-integration of exogenous shRNA (Hitt et al., 1997), although adenoviral vectors are occasionally used in in vitro experiments. Also, long-term exposure to adenoviruses in humans could cause respiratory, gastrointestinal, and eye infections, thereby triggering a rapid immune response with potentially dangerous consequences (Nayak and Herzog, 2010). Therefore, a more suitable viral vector without body immunity needs to be identified. In conclusion, we developed an efficient vehicle to study HBs. 


\section{ACKNOWLEDGMENTS}

Research supported by the Nature Science Foundation of China (\#30771924) and the Natural Science Foundation Project of CQ CSTC (\#2010BB5359).

\section{REFERENCES}

Elbashir SM, Lendeckel W and Tuschl T (2001). RNA interference is mediated by 21- and 22-nucleotide RNAs. Genes Dev. 15: 188-200.

Elbashir SM, Harborth J, Weber K and Tuschl T (2002). Analysis of gene function in somatic mammalian cells using small interfering RNAs. Methods 26: 199-213.

Guo S and Kemphues KJ (1995). par-1, a gene required for establishing polarity in C. elegans embryos, encodes a putative Ser/Thr kinase that is asymmetrically distributed. Cell 81: 611-620.

Hitt MM, Addison CL and Graham FL (1997). Human adenovirus vectors for gene transfer into mammalian cells. $A d v$. Pharmacol. 40: 137-206.

Kapadia SB, Brideau-Andersen A and Chisari FV (2003). Interference of hepatitis C virus RNA replication by short interfering RNAs. Proc. Natl. Acad. Sci. U. S. A. 100: 2014-2018.

Livak KJ and Schmittgen TD (2001). Analysis of relative gene expression data using real-time quantitative PCR and the $2^{(-\Delta \Delta C(T))}$ method. Methods 25: 402-408.

Luo J, Deng ZL, Luo X, Tang N, et al. (2007). A protocol for rapid generation of recombinant adenoviruses using the AdEasy system. Nat. Protoc. 2: 1236-1247.

Margolis HS (1998). Hepatitis B virus infection. Bull. World Health Organ 76 (Suppl 2): 152-153.

McConnell MJ and Imperiale MJ (2004). Biology of adenovirus and its use as a vector for gene therapy. Hum. Gene Ther. 15: 1022-1033.

Nayak S and Herzog RW (2010). Progress and prospects: immune responses to viral vectors. Gene Ther. 17: 295-304.

Paddison PJ, Caudy AA, Bernstein E, Hannon GJ, et al. (2002). Short hairpin RNAs (shRNAs) induce sequence-specific silencing in mammalian cells. Genes Dev. 16: 948-958. 